\title{
円弧状の仕上げ刃を持つ旋削用チップの切削性能
}

\author{
和田 任弘, 中西 順 \\ 奈良工業高等専門学校機械工学科, $=$ 639-1080 大和郡山市矢田町 22.
}

\section{Cutting Performance of a Turning Insert Having an Arc-shaped Finishing Edge}

\author{
Tadahiro Wada and Jun Nakanishi \\ Department of Mechanical Engineering, Nara National College of Technology, 22 Yata-cho, Yamatokoriyama 639-1080, Japan.
}

Received August 21, 2009

\section{SYNOPSIS}

In turning operations, it is effective to use a larger corner radius or a lower feed rate to obtain a good machined surface. However, turning at lower feed rates decreases productivity and it has a negative influence on the turning operation because of the continuous chip. In turning of a shaft having a step of specified corner R, it is important whether the corner radius of the turning insert is the same as specified corner $\mathrm{R}$ or lower than it. A turning tool with a large corner radius cannot adapt to cutting a shaft having a step of specified corner $\mathrm{R}$. In this study, the surface roughness, cutting force, and tool wear were experimentally investigated in order to clarify the cutting performance of the turning insert having an arc-shaped finishing edge formed at the point of intersection between the corner radius and the end cutting edge. Work piece material SKD11 was turned with two kinds of turning inserts that had different radii of the arc-shaped finishing edge.

The main results obtained are as follows. (1) The machined surface of the insert having an arc-shaped finish edge was better than that of the normal insert. (2) The wear progress of the insert having an arc-shaped finish edge was slightly slower than that of the normal insert. (3) The cutting force of the insert having an arc-shaped finish edge was almost the same as that of the normal insert.

\section{KEY WORDS}

cutting performance, turning insert, arc-shaped finishing edge, surface roughness, tool wear

\section{1 緒言}

切削仕上げ面の特性は, 仕上げ面粗さ, うねり, 加工変質 層, 残留応力などを媒体として評価できる ${ }^{1)}$ が, 仕上げ面粗 さは, 摩擦, 摩耗, 密閉, 漏洩など表面の接触問題を考える 上で非常に重要となる ${ }^{2)}$. 旋削では，理想的な仕上げ面粗さ は工具刃部形状と送りSによって決まる.例えば, 刃部にコ一 ナ半径 $\mathrm{r}$ を有する片刃バイト(横切れ刃角 $0^{\circ}$ )を用い, $2 \mathrm{r} よ り$ 低い送り $S$ で旋削した場合, 仕上げ面粗さの理論値 (最大高 さ $\mathrm{Rz})$ は， $\mathrm{S}^{2} /(8 \mathrm{r})$ で近似できる.このため，良好な切削仕上 げ面を得るには，送りを低くするか，コーナ半径を大きくす ることが有効である，送りを低くすると，作業能率の低下や 切りくずが薄く柔軟になるため切りくず処理性が低下する. コーナ半径を大きくすれば高送りで切削することができる. しかし, シャフトなどの段付軸は旋削によって加工される場
合も多く, 隅 $\mathrm{R}$ を持つ段付軸を加工する場合, 段差には工具 刃部の円弧が転写される.このため, バイトのコーナ半径を 隅 R と同じ，あるいは小さくする必要があり，コーナ半径は 機械部品の隅 Rから制限を受ける。 そこで, 横切れ刃直線部 とコーナ, および前切れ刃直線部とコーナの接線部に直線状 の仕上げ刃(ワイパー刃, さらい刃の名称で呼ばれている)を 設けた工具が市販されている. 特に, 外周旋削では, 前切れ 刃側に設けた仕上げ刃は，高送り旋削でも良好な仕上げ面が 得られる.しかし, この方法では, 加工プログラムの修正や, 隅R切削では加工プログラムの修正やコーナ半径の補正が必 要になる.

本研究では, 前切れ刃とコーナの接線部に円弧状の仕上げ 刃を設けたバイト，すなおちコーナ部が2つの円弧からなる バイトを考案した. 次に, このバイトで, SKD11焼なまし材 
の旋削を行い, 仕上げ面粗さ, 切削抵抗, 工具摩耗を調べた.

\section{2 実験方法}

被削材にはダイス鋼 SKD11 焼なまし材 (224HB) を使用し た。被削材の化学成分および性質を Table 1 に示す.

Fig.1に使用した旋削用チップの刃部形状を示す．ここで, $\mathrm{S}$ は送りの方向, $\mathrm{a}$ は切込みを示す。コーナ部は 2 つの弧, すなわち横切れ刃側の半径 $\mathrm{r}($ 円弧 $\mathrm{AB}$ ), および前切れ刃側の 半径 $\mathrm{R}$ (円弧 $\mathrm{BC}$ ) から構成されている. Table 2 に, 本研究で 使用した刃部の諸元を示す. $\mathrm{r}, \alpha$ は，それぞれ $0.4 \mathrm{~mm}, 30^{\circ}$ と 一定とし， R を変化させた. Type III は， r = R の場合で通常 の刃部形状になる.すなわち, コーナ半径 $0.4 \mathrm{~mm}$ の旋削用 チップ(TNGA160404型)を市販状態で使用した.この市販旋 削用チップを $\square 25 \mathrm{~mm} \times 25 \mathrm{~mm}$ バイトホルダに取付けた場合,

Table 1Chemical composition of work piece material (SKD11, 224HB).

\begin{tabular}{|c|c|c|c|c|c|}
\hline $\mathrm{C}$ & $\mathrm{Cr}$ & $\mathrm{Mo}$ & $\mathrm{Mn}$ & $\mathrm{Si}$ & $\mathrm{V}$ \\
\hline 1.47 & 11.5 & 0.82 & 0.37 & 0.32 & 0.20 \\
\hline
\end{tabular}

Chemical composition (mass\%)

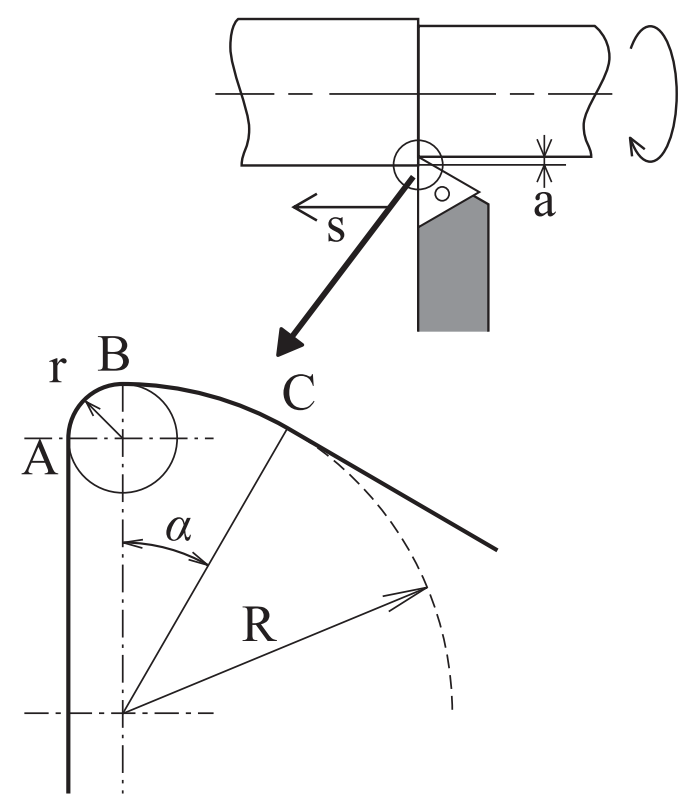

Fig.1 Configuration of cutting part.

Table 2 Geometry of cutting part.

\begin{tabular}{|c|c|c|c|}
\hline & Type I & Type II & Type III \\
\hline $\mathrm{R}(\mathrm{mm})$ & 1.2 & 2.4 & 0.4 \\
\hline $\mathrm{r}(\mathrm{mm})$ & \multicolumn{3}{|c|}{0.4} \\
\hline$\alpha(\mathrm{deg})$ & \multicolumn{3}{|c|}{30} \\
\hline
\end{tabular}

工具形状は $\left(-6^{\circ},-6^{\circ}, 6^{\circ}, 6^{\circ}, 30^{\circ}, 0^{\circ}, 0.4 \mathrm{~mm}\right)$ となる. ここで, 7 つの数字は, 前から順に前すくい角, 横すくい角, 前逃げ 角, 横逃げ角, 前切刃角, 横切刃角, コーナ半径 (ノーズ半 径)である ${ }^{3)}$. Type I, Type II は, Type III (TNGA160404 型 旋削用チップ)の刃部をダイヤモンド砥石によりコーナ部が 2 つの円弧になるように成形したものである.なお， 3 種類の 工具切れ刃には $\left(0.03 \mathrm{~mm} \times 20^{\circ}\right)$ のチャンファホーニングを施 した. また, いずれの工具材種も, 超硬合金 P10 種で, コー ティングを施していない状態で使用した.

使用工作機械は，無段変速装置付き高速精密旋盤 (昌運工 作所製，ST5×1000 型， $7.5 / 11 \mathrm{~kW} ， 8 \sim 2500 \mathrm{~min}^{-1}$ ) である.

Table 3 に示す切削条件で被削材の外周旋削を乾式で行い, 仕上げ面粗さ, 切削抵抗, および工具摩耗を調べた。仕上げ 面粗さの測定には, 東京精密社製サーフコム1800A 型触針式 表面粗さ測定器を用い, 送り方向の仕上げ面のプロフィール を記録し, 最大高さ Rz 測定した. 切削抵抗は, 共和電業社 製 TD 型工具動力計, 動的ひずみ測定器にて測定し, レコー ダに記録させた. なお, 工具摩耗を調べる実験では, 送り 0.3 , $0.4 \mathrm{~mm} / \mathrm{rev}$ で行った.

\section{3 実験結果および考察}

3.1 仕上げ面粗さ

Fig.2 に送りが仕上げ面粗さ (最大高さ Rz) に及ぼす影響を 示す、いずれのチップも理論值と測定值はよく似ており，送 りの増加につれ仕.上げ面粗さが大きくなる. Type IIの仕上げ 面粗さが最も小さい. 送り $0.4 \mathrm{~mm} / \mathrm{rev}$ の場合, Type I の仕上 げ面粗さは Type III に対して約 $1 / 2$ 倍, Type II の仕上げ面粗 さはType IIIに対して約 $1 / 3$ 倍である. 理論粗さを計算すると 最大3倍程度差があるのでこの結果になるものと推測される.

Table 3 Cutting conditions.

\begin{tabular}{|ll|c|}
\hline Cutting speed $(\mathrm{m} / \mathrm{s})$ & V & 2.5 \\
\hline Feed rate $(\mathrm{mm} / \mathrm{rev})$ & $\mathrm{S}$ & $0.1 \sim 0.5$ \\
\hline Depth of cut $(\mathrm{mm})$ & $\mathrm{a}$ & 0.5 \\
\hline Cutting method & Dry \\
\hline
\end{tabular}

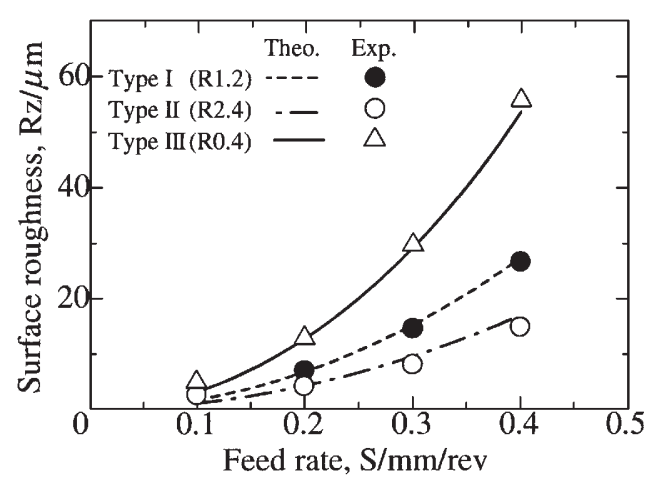

Fig.2 Relation between feed rate and surface roughness. 
このことから，円弧状の仕上げ刃を持つ旋削用チップを使用 すると，高送り旋削でも良好な切削仕上げ面が得られる.

3.2 切削抵抗

Fig.3に送りが切削抵抗 3 分力に及ぼす影響を示す.いずれ のチップも送りが高くなると切削抵抗 3 分力は増加するが, 刃部形状による影響はほとんご見られない。この理由を次に 示す．すなわち，切削抵抗 3 分力は, 被削材, 切削条件, 工 具形状に依存する. 特に, 本研究のように送りを変化させた 場合, 切削抵抗主分力は, 切削面積に依存し, 送り分力, 背 分力は，切削面積および切りくず流出方向に依存する．たと えば，送り $0.4 \mathrm{~mm} / \mathrm{rev}$ ，切込み $0.5 \mathrm{~mm}$ における Type II, Type III の切削面積を計算すると, Type II の切削面積 $0.197 \mathrm{~mm}^{2}$ に 対し Type III の切削面積は $0.193 \mathrm{~mm}^{2}$ で大差ない. また, Collwellの切りくず流出方向の仮定から切りくずの流出角 $\eta_{\mathrm{c}}{ }^{4)}$ を計算すると，Type III $\eta_{\mathrm{c}}=54.8^{\circ}$ に対し，Type III の $\eta_{\mathrm{c}}=53.4^{\circ}$ で大差ない.

以上のことから, 切削面積および切りくず流出方向に大差 ないことから, 切削抵抗 3 分力は, 刃部形状の影響を受けな かったと考えられる.

3.3 工具摩耗

切削の進行に連れ工具は摩耗し, 切削性能も変化する.

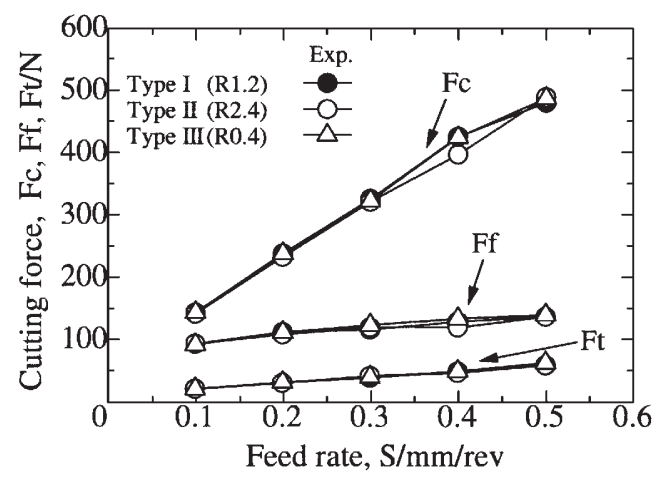

Fig.3 Relation between feed rate and cutting force (Fc: Principal force, Ft: Thrust force, Ff: Feed force).
Fig.4に工具の摩耗状態を示す. 送りは $0.3 \mathrm{~mm} / \mathrm{rev}$ の場合であ る. 工具に凝着物が見られるが，いずれのチップも逃げ面摩 耗が主な工具損傷である，そこで, 逃げ面摩耗幅の最大值 VBmax を測定した. Fig.5 に工具の摩耗進行を示す. 円弧状 の仕上げ刃を持つチップ Type I, II の摩耗進行は, Type III の 摩耗進行に比べやや遅い.これは, 前切れ刃側を円弧にする ことにより，わずかだが切削に関与するすくい面の面積が増 え，すくい面における熱および応力集中が軽減され，工具の 摩耗進行が遅くなったと考元られる.なお，被削材が高硬度 でないにもかかわらず切削距離 $0.6 \sim 0.8 \mathrm{~km}$ 程度で逃げ面摩耗 幅の最大值が $0.2 \mathrm{~mm}$ 程度になった.これには, 次の理由が考 えられる.すなわち, Table 1に示したように, SKD11には, Cが 1.47 mass\%, Crが 11.5 mass\% 之, 通常の炭素鋼に比べ, C およびCrが多く含まれている. 特に SKD11 は極めて粗大 化した炭化物 $\mathrm{Cr}_{7} \mathrm{C}_{3}$ や $\mathrm{Fe}_{3} \mathrm{C}$ が存在し，これらは極めて硬い. 従って, この炭化物が工具表面を引っかいて工具の一部が削 り取られ，工具摩耗が大きくなったと考えられる．さらに， SKD11には, Crが多く含まれているため, Fig.4に示したよ うに通常の鋼材の旋削に比べ工具に凝着物が付着しやすい. このことから, 凝着物が工具から剥離・脱落するとき, 工具 の一部も切りくずと一緒に持ち去られ, 工具摩耗が大きく

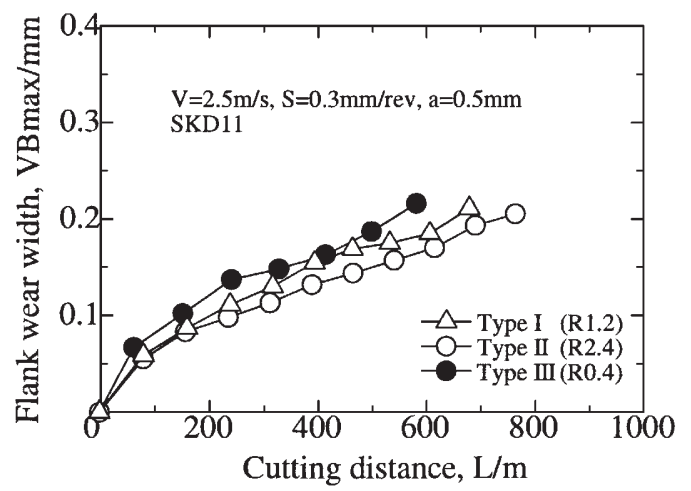

Fig.5 Relation between cutting distance and flank wear width at feed rate of $0.3 \mathrm{~mm} / \mathrm{rev}$.
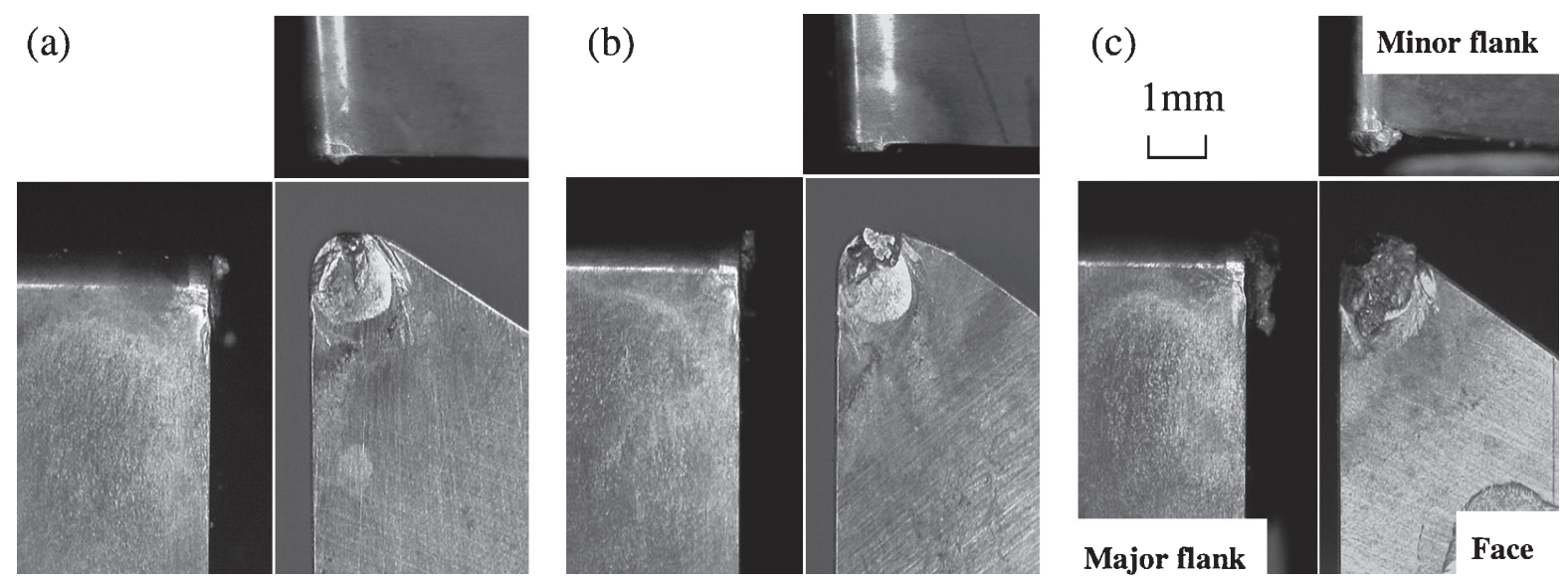

Fig.4 Tool wear at feed rate of $0.3 \mathrm{~mm} / \mathrm{rev}$. (a): Type I (Cutting distance $\mathrm{L}=0.7 \mathrm{~km})$, (b): Type II $(\mathrm{L}=0.8 \mathrm{~km})$, (c): Type III (L=0.6 km) 


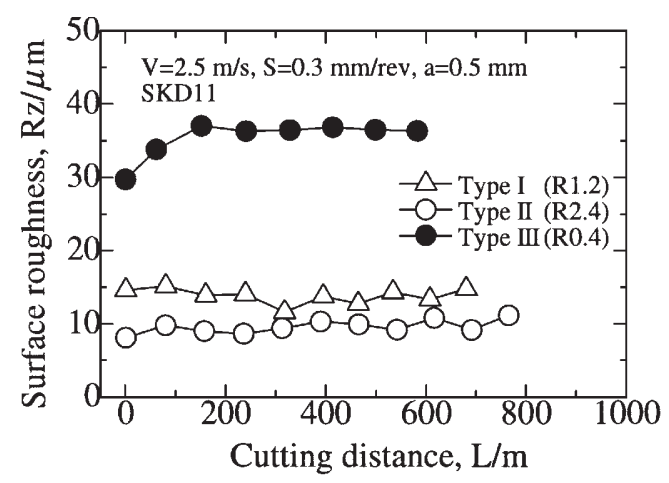

Fig.6 Relation between cutting distance and surface roughness at feed rate of $0.3 \mathrm{~mm} / \mathrm{rev}$.

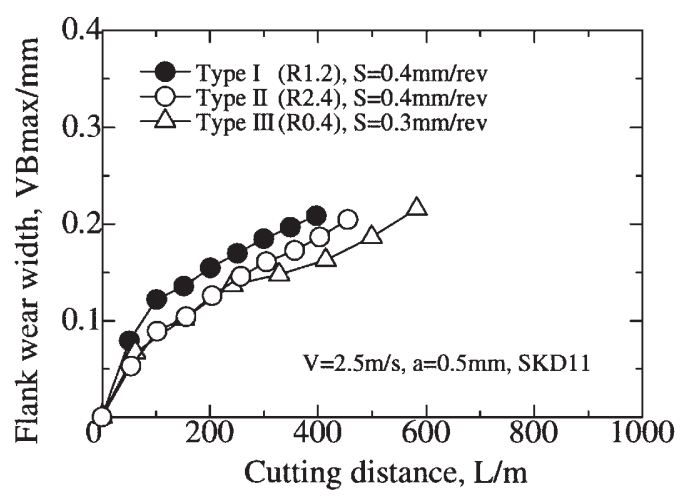

Fig.7 Relation between cutting distance and flank wear width.

なったと考えられる。これらには, 耐凝着性に優れた硬質物 質をコーティングすることによって工具摩耗の低減が期待で きる。

Fig.6に, 切削距離が仕上げ面粗さに及ぼす影響を示す. Type IIIの場合, 切削の進行につれ仕上げ面粗さが増加する傾 向が見られる. Type I, II の場合, 切削が進行し工具が摩耗し ても，仕上げ面粗さはあまり変化しない.

最後に, Type I, IIのバイトで送り $0.4 \mathrm{~mm} / \mathrm{rev}$ で高送り旋削 を行い, 切削距離が工具摩耗ならびに仕上げ面粗さに及ぼす 影響について調べた. なお, Type IIIのチップについては, 送 り $0.3 \mathrm{~mm} / \mathrm{rev}$ の場合を示す. Fig.7に, 工具の摩耗進行を示す. 送り $0.3 \mathrm{~mm} / \mathrm{rev}$ の Type III の摩耗進行が最も遅くなっている が, これは, Type I, IIに比べ送りが低いため, 切削温度が低 くなり, 工具の摩耗進行が遅くなったと考えられる. 逃げ面 摩耗幅の最大值 $0.2 \mathrm{~mm}$ にお污被削材の除去量 (=切削距離 ×送り ×切込み) を比較すると, Type II の除去量が最も多い.

Fig.8に, 切削距離が仕上げ面粗さに及ぼす影響を示す. 切 削初期における仕上げ面粗さを比較すると, Type I と IIIの仕 上げ面粗さに大差なく, Type II の仕上げ面粗さが最も小さ い. 切削距離の増加につれ，バイトType III の仕上げ面粗さ は大きくなるが, バイトType I とII の仕上げ面粗さはあまり 変化しない.

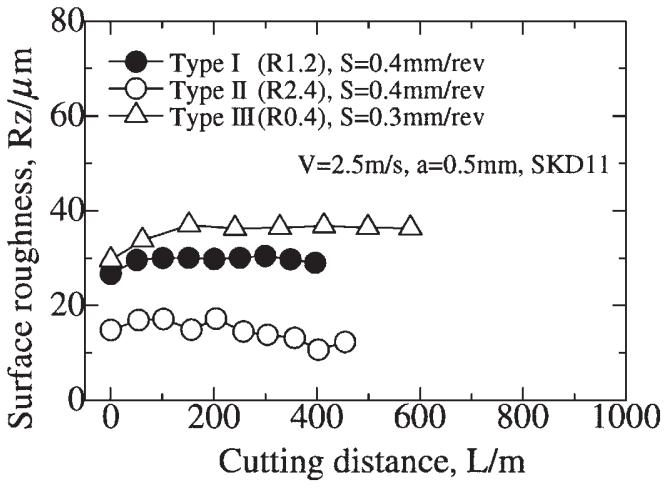

Fig.8 Relation between cutting distance and surface roughness.

以上のことから, 前切れ刃とコーナの接線部に円弧状の仕 上げ刃を設けたバイトで旋削を行う場合, 通常のバイトに比 べ高送り旋削を行うことにより大きな材料除去が得られ，し かも良好な仕上げ面粗さを得ることが可能である.

\section{4 結 言}

円弧状の仕上げ刃を持つ旋削用チップ, すなわち横切れ刃 側の半径 $\mathrm{r}$ と前切れ刃側の半径 $\mathrm{R}$ の 2つ半径で構成される旋 削用チップで外周旋削を行い, 仕上げ面粗さ, 切削抵抗, 工 具摩耗を調べた.

得られた主な結果は次の通りである.

(1) 円弧状の仕上げ刃を持つチップの仕上げ面粗さは, 通常 のチップに比べ小さかった. また, 仕上げ面粗さは, 前切 れ刃側の半径 Rが大きい方が小さかった.

(2) 円弧状の仕上げ刃を持つチップの摩耗進行は, 通常の チップに比べ,やや遅かった。

(3) 前切れ刃側の円弧Rは切削抵抗に影響を及ぼさなかった. 以上のことから, 円弧状の仕上げ刃を持つ旋削用チップは, 送りを高くして旋削することができるので, 作業能率 (切り くず処理性も含めて) 向上に有効であることが分かった.

\section{謝 辞}

旋削用チップの刃部成形にご協力いただきました侏タンガ ロイに感謝の意を表します。

\section{文献}

1) Jpn. Soc. for Precision Engineering: Handbook of Precision Machining, CORONA PUBLISHING Co., LTD., (1992) 111.

2) O. Kouji, et al.: Riron Sesaku Kougaku, Genzaikougakusya. (1979) 121

3) E. Sentoku, M. Kito, and T. Nakagawa: "Research on the Surface Roughness and Friction Coefficient in Cutting of Cast Iron", J. Jpn. Soc. Powder Powder Metallurgy, 49 (2002) 290-293.

4) Jpn. Soc. for Precision Engineering: Handbook of Precision Machining, CORONA PUBLISHING Co., LTD., (1992) 18. 